\author{
Jurnal llmu Administrasi Publik 6 (1) (2018): 100-110 \\ Jurnal Administrasi Publik \\ http://ojs.uma.ac.id/index.php/publikauma
}

\title{
Pemodelan Faktor-Faktor yang Mempengaruhi Indeks Kedalaman Kemiskinan dan Indeks Keparahan Kemiskinan Kabupaten/Kota di Sumatera Utara Menggunakan Regresi Data Panel
}

\author{
Juhar Monang S. Tambun dan Rita Herawaty * \\ Fungsional Statistisi BPS Provinsi Sumatera Utara, Indonesia
}

Diterima Februari 2018; Disetujui April 2018; Dipublikasikan Juni 2018

\begin{abstract}
Abstrak
Selama kurun waktu 2012-2015 kemiskinan yang diukur dari indeks kedalaman kemiskinan dan indeks keparahankemiskinan masih belum berkurang secara signifikan. Penelitian ini bertujuan untuk mengetahui pemodelan yang tepat dalam mencari faktor-faktor yang mempengaruhi indeks kedalaman kemiskinan dan indeks keparahan kemiskinan. Data yang digunakan adalah data sekunder yang diperoleh dari Badan Pusat Statistik Provinsi Sumatera Utara dari tahun 2012-2015. Adapaun variabel respon yang digunakan dalam penelitian ini adalah indeks kedalaman kemiskinan (PI) dan indeks keparahan kemiskinan (P2).Sementara variabel bebas yang digunakan dalam penelitian ini dari aspek demografi yaitu tingkat pengangguran terbuka dan tingkat partisipasi angkatan kerja, dari aspek ekonomi yaitu pertumbuhan ekonomi, pertumbuhan PAD, dan pertumbuhan pengeluaran rumah tangg, dan dari aspek pendidikan yaitu angka melek huruf, ratarata lama sekolah (MYS), dan harapan lama sekolah (EYS). Model yang terbaik yang diperoleh adalah Random EffectModel (REM) dimana terdapat efek cross section dan efek waktu terhadap pemodelan. Adapun faktor yang mempengaruhi indeks kemiskinan dan indeks kedalaman kemiskinan adalah pertumbuhan pengeluaran rumah tangga, angka melek huruf, dan rata-rata lama sekolah.
\end{abstract}

Kata Kunci : indeks kedalaman kemiskinan, indeks keparahan kemiskinan, regresi panel, random effect model

\begin{abstract}
During the period 2012-2015 poverty measured from the indices of poverty depth and poverty indices are still not significantly reduced. This study aims to find out the proper modeling in looking for factors that affect the index of poverty depth and poverty severity index. The data used are secondary data obtained from Central Bureau of Statistics of North Sumatra Province from 2012-2015. Adapaun response variable used in this research is the index of poverty depth (PI) and poverty severity index (P2). While the independent variables used in this study from the demographic aspects are open unemployment rate and labor force participation rate, from the economic aspect that is economic growth, PAD growth, and growth in household expenditures, and from educational aspects such as literacy rate, average school duration (MYS), and school life expectancy (EYS). The best model obtained is the Random EffectModel (REM) where there are cross section effects and time effects on the modeling. The factors that affect the poverty index and poverty depth index are the growth of household expenditure, literacy rate, and the average length of school.
\end{abstract}

Keywords : index of poverty depth, index of poverty severity, panel regression, random effect model

How to Cite : Tambun, S.M.J., dan Herawaty,R., (2018). Pemodelan Faktor-Faktor yang Mempengaruhi Indeks Kedalaman Kemiskinan dan Indeks Keparahan Kemiskinan Kabupaten/Kota di Sumatera Utara Menggunakan Regresi Data Panel 6 (1): 100-110

*Corresponding author:

P-ISSN-2549-9165

E-mail: ritabangun31@yahoo.co.id

e-ISSN -2580-2011 
PENDAHULUAN

Salah satu bukti keberhasilan dalam pembangunan adalah pengendalian kemiskinan. Namun kemiskinan masih tetap menjadi permasalahan klasik yang masih belum tuntuas di Indonesia terkhusus di Provinsi Sumatera Utara. Pada tahun 2015 jumlah penduduk miskin di Provinsi Sumatera Utara mencapai 1.508.140 jiwa atau mencapai 10,79 persen dari total penduduk Provinsi Sumatera Utara. Angka ini justru mengalami peningkatan seiring berjalnnya waktu dari periode-periode sebelumnya. Selain itu, ketimpangan kemiskinan yang diukur dari indeks kedalaman kemiskinan dan indeks keparahan kemiskinan menunjukkan angka yang cenderung stagnan dari tahun ke tahun. Oleh sebab itu, perlu diketahui faktor apa saja yang mempengaruhi kemiskinan di Provinsi Sumatera Utara.

Adapun faktor-faktor yang diduga memiliki pengaruh terhadap pengentasan kemiskinan yaitu dari aspek demografi, aspek ekonomi, dan aspek pendidikan. Aspek demografi dilihat dari variabel tingkat pengangguran terbuka (TPT), dan tingkat partisipasi angkatan kerja (TPAK). Aspek ekonomi dilihat dari variabel pertumbuhan ekonomi, pendapatan asli daerah, dan pengeluaran rumah tangga.

Metode yang digunakan dalam pencarian model yang tepat dalam penelitian in adalah dengan menggunakan analisis regresi data panel yang melibatkan data runtut waktu (cross section) dan data silang (time series). Adapun keuntungan menggunakan data panel adalah meningkatkan degree of freedom sehingga mengurangi kolinearitas antar variabel penjelas (Hsiao, 1986) serta menggabungkan informasi dari data time series dan cross section sehinga dapatmengatasi masalah yang timbul ketika ada penghilangan variabel (Agus Widarjono, 2009).

Berdasarkan uraian yang telah dijelaskan di atas, perlu dilakukan penelitian tentang actor-faktor apa saja yang berpengaruh terhadap tingkat kemiskinan di Provinsi Sumatera Utara melalui pemodelan regresi data panel. Adapun manfaat yang diharapkan dari penelitian ini adalah untuk memberikan informasi bagi pemerintah Provinsi Sumatera Utara dalam menentukan arah kebijakan pembangunan masing-masing kabupaten/kota di Provinsi Sumatera Utara

\section{Metode Penelitian}

Data yang digunakan dalam penelitian ini merupakan data sekunder yang diperoleh dari Badan Pusat Statistik (BPS) Sumatera Utara. Adapun variabel respon yang digunakan adalah Indeks Kedalaman Kemiskinan ( $\mathrm{Pl}$ ) dan Indeks Keparahan Kemiskinan (P2)untuk 33 kabupaten/kota di Provinsi Sumatera Utara tahun 2012-2015. Variabel actor or yaitu actor-faktor yang diduga mempengaruhi kemiskinan di Provinsi sumatera utara meliputi variabel demografi (TPT, TPAK) variabel ekonomi (EG, LnPAD, LnEXP) dan variabel pendidikan 
(AMH, MYS, EYS) seperti yang disajikan pada tabel 1.

Tabel. 1 Variabel Penelitian

\begin{tabular}{|c|c|c|c|}
\hline Variabel & Simbol & Keterangan & Satuan \\
\hline \multirow{2}{*}{ Respon } & $\mathrm{Pl}$ & Indkes Kedalaman Kemiskinan & - \\
\hline & P2 & lndeks Keparahan Kemiskinan & - \\
\hline \multirow{9}{*}{ Prediktor } & TPT & Tingkat Pengangguran Terbuka & Persen \\
\hline & ТРAK & Tingkat Partisipasi Angkatan Kerja & Persen \\
\hline & EG & Pertumbuhan Ekonomi & Persen \\
\hline & LnPAD & Pertumbuhan Pendapatan Asli Daerah & Persen \\
\hline & & Pertumbuhan Pengeluaran Rumah & \\
\hline & LnEXP & Tangga & Persen \\
\hline & $\mathrm{AMH}$ & Angka Melek Huruf & - \\
\hline & MYS & Rata-rata Lama Sekolah & - \\
\hline & EYS & Harapan Lama Sekolah & - \\
\hline
\end{tabular}

Penelitian ini menggunakan data panel yang terdiri dari data time series dari tahun 2012 hingga 2015 dan data cross section mencakup 33 kabupaten/kota yang ada di Provinsi Sumatera Utara. Total observasi yang digunakan dalam penelitian ini adalah 132 unit.

Tahapan pemilihan model terbaik dilakukan dengan terlebih dahulu menentukan ketiga model regresi panel yaitu common effect model (CEM), fixed effect model (FEM), dan Random effect model (REM). Kemudian model estimasi

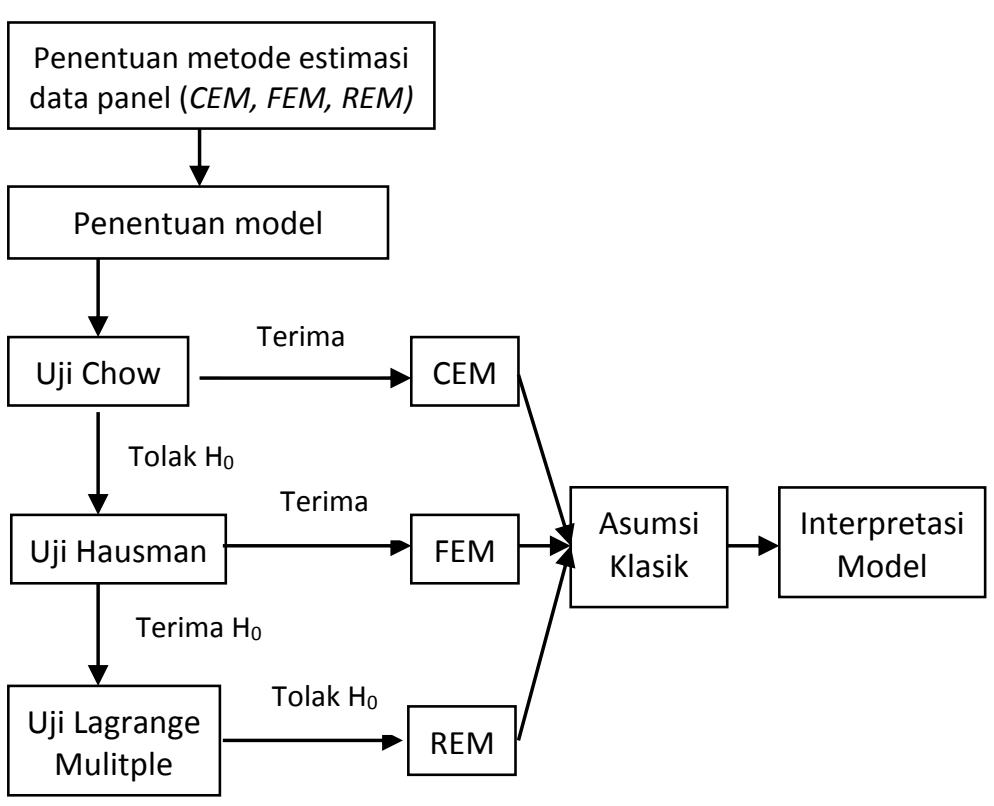
terbaik dengan melakukan pengujian terhadap ketiga model tersebut dengan uji Bagan 1. Tahapan Pemilihan Model Chow, uji Hausman, dan uji Lagrange Multiple seperti pada bagan dibawah. 


\section{Hasil dan Pembahasan}

\section{Pengujian Signifikansi ModelCommone \\ Effects atau Fixed Effects (Uji Chow)}

Uji Signifikansi fixed effect dilakukan dengan uji Chow dengan uji F statistik. Uji $\mathrm{F}$ ini digunakan untuk mengetahui apakah teknik regresi data panel dengan model fixed effect lebih baik dari model regresi common effects.

$$
\begin{aligned}
& H_{0}: \alpha_{1}=\alpha_{2}=\ldots=\alpha_{33}=O \text { (intersep untuk } \\
& \text { semua kabupaten adalah sama) } \\
& H_{1}: \text { minimal ada satu } \alpha_{i} \neq 0 \text { dimana } i= \\
& \text { l,2,...,n } \\
& \text { Wilayah kritis } F_{(\alpha ; n-1 ; n T-n-k)}=F_{(0,05 ; 32 ; 91)} \\
& \text { Statistik Uji F : } \\
& F=\frac{\left(R S S_{1}-R S S_{2}\right) /(n-1)}{R S S_{2} /(n T-n-k)}
\end{aligned}
$$

Tabel. 2 Hasil Uji Chow untuk Pı dan P2

\begin{tabular}{ccccc}
\hline variabel respon & F-hitung & d.f & P-value & Keputusan \\
\hline P1 & 20,253 & 32,91 & 0,000 & Tolak Ho \\
\hline P2 & 9,45 & 32,91 & 0,000 & Tolak Ho \\
\hline
\end{tabular}

Berdasarkan hasil perhitungan, diperoleh nilai $F$ hitung sebesar 20,253 (dengan $P I$ sebagai variabel responnya) dan 9,453 (dengan P2 sebagai variabel responnya).yang lebih besar daripada nilai $F$ dengan derajat bebas 32 dan 91 pada tingkat signifikansi 0,05 yaitu 1,57. Selain itu nilai signifikansi lebih kecil dari $\alpha=5 \%$. Dengan demikian, hipotesis nol ditolak sehingga dapat disimpulkan bahwa pada tingkat kepercayaan 95 persen, intersep untuk setiap kabupaten tidak sama. Oleh karena itu, model fixed effects lebih baik daripada model common effects.

\author{
Pengujian Signifikansi Model Fixed Effects \\ atau Model Random Effects (Uji Hausman) \\ Uji Hausman dimaksudkan untuk \\ memilih model estimasi terbaik antara \\ model fixed effects atau model random \\ effects. Statistik uji Hausman mengikuti \\ distribusi statistik Chi Square dengan \\ derajat bebas sebanyak jumlah variabel \\ bebas dalam model. \\ $H_{0} \quad: \quad \operatorname{Cov}\left(u_{1_{a}} X_{i t}\right)=0$ (Model random \\ effects lebih baik daripada model fixed \\ effects)
}


$H_{1} \quad \operatorname{Cov}\left(u_{1} X_{i t}\right) \neq 0$ (Model fixed effects Statistik Uji Hausman :

lebih baik daripada model random effects)

Wilayah kritis $: \chi_{(\alpha, k)} \chi_{(0,05,8)}=14,067$

$$
W=\chi^{2}{ }_{o b s}=\left[\hat{\beta}-\hat{\beta}_{G L S}\right]^{\prime} \hat{\Sigma}^{-1}\left[\hat{\beta}-\hat{\beta}_{G L S}\right]
$$

Tabel. 3. Uji Hausman untuk $P I$ dan $P 2$

\begin{tabular}{ccccc}
\hline variabel respon & Chi-Squrare & d.f & P-value & Keputusan \\
\hline$P l$ & 9,7116 & 8 & 0,2859 & Gagal tolak Ho \\
\hline$P 2$ & 10,00 & 8 & 0,2650 & Gagal tolak Ho
\end{tabular}

Berdasarkan hasil perhitungan, diperoleh nilai Hausman-statistic sebesar 9,7116 (dimana PI sebagai variabel responnya) dan 10,00 (dimana P2 sebagai variabel responnya).Nilai ini lebih kecil dari wilayah kritis dengan derajat bebas 8 pada tingkat signifikansi 0,05 yaitu 15,507. Selain itu nilai $p$-valuelebih besar dari $\alpha=5 \%$. Dengan demikian, hipotesis nol diterima sehingga dapat disimpulkan bahwa model yang tepat untuk regresi data panel adalah model random effectsdaripada model fixed effects.

\section{Pengujian Signifikansi Model Common effects atau Model Random Effects (Uji Lagrange Multiplier)}

Uji LM ini didasarkan pada distribusi chi-squares dengan degree of

freedom sebesar jumlah variabel bebas. Jika nilai LM statistik lebih besar dari nilai kritis statistik chi-squares maka kita menolak hipotesis nul, yang artinya estimasi yang tepat untuk model regresi data panel adalah metode Random Effect dari pada metode Common Effect.

$H_{0} \quad: c=0, d=0$ (tidak ada efek crosssection dan waktu secara bersamaan terhadap model)

$H_{1}: c \neq 0, d \neq 0$ (terdapat efek cross-section atau efek waktu terhadap model)

Wilayah kritis : $\chi_{(\alpha, k)}: \chi_{(0,05,8)}$

Statistik Uji Hausman :

$$
L M=\frac{n T}{2(T-1)}\left[\frac{\sum_{i=1}^{n}\left(T \hat{e}_{i}\right)^{2}}{\sum_{i=1}^{n} \sum_{t=1}^{T} \hat{e}_{i t}^{2}}-1\right]^{2}
$$

Tabel. 4 Uji Lagrange Multiplier untuk P1 dan P2

\begin{tabular}{cccc}
\hline variabel respon & Breusch-Pagan & P-value & Keputusan \\
\hline P1 & 124 & 0,000 & Terima Ho \\
\hline P2 & 880,217 & 0,000 & Terima Ho \\
\hline
\end{tabular}


Berdasarkan hasil perhitungan, diperoleh nilai nilai signifikansi LM-statistic untuk kedua efek (cross-section \& time) lebih kecil dari 0,05 sehingga disimpulkan bahwa terdapat efek cross-section dan waktu secara bersama-sama pada model regresi panel. Hasil perhitungan ini juga menunjukkan bahwa model random effects adalah model terbaik dalam estimasi faktor yang mempengaruhi indeks kdalaman kemiskinan (Pl) dan indeks keparahan kemiskinan (P2) di Provinsi Sumatera Utara.

\section{Pengujain Asumsi Klasik}

Pengujian asumsi dilakukan untuk memastikan bahwa model yang terpilih telah memenuhi asumsi yang telah ditentukan.
Estimasi Generalized Least Squares (GLS) pada model random effecttelah mampu mengatasi asumsi heteroskedastis dan autokorelasi dalam model (Gujarati, 2003). Oleh karena itu, asumsi yang harus diperhatikan adalah asumsi normalitas dan non-multikolinearitas.

\section{Uji Normalitas (uji Jarque Berra)}

$H_{0}: e_{i} \sim B\left(0, \sigma^{2}\right)$, redisual mengikutir distribusi normal

$H_{1}=e_{i} * N\left(0, e^{2}, \quad\right.$ residual tidak mengikuti distribusi normal. Wilayah Kritik : Tolak $\mathrm{H}_{0}$ jika $P$-value $<\alpha$ Statistik Uji :

$$
I B=\frac{T}{6}\left(S^{2}+\frac{1}{4}(K-3)^{2}\right)
$$

Tabel 5. Uji Normalitas Jarque Berra Tiap Kabupaten/Kota untuk Indeks Kedalaman Kemiskinan (PI) dan Indeks Keparahan Kemiskinan(P2)

\begin{tabular}{|c|c|c|c|c|c|c|c|c|c|}
\hline \multirow[b]{2}{*}{ Kab/Kota } & \multicolumn{2}{|c|}{$P l$} & \multicolumn{2}{|c|}{$P 2$} & \multirow[b]{2}{*}{ Kab/Kota } & \multicolumn{2}{|c|}{$P l$} & \multicolumn{2}{|c|}{$P 2$} \\
\hline & $\begin{array}{c}\text { Jarque- } \\
\text { Bera }\end{array}$ & 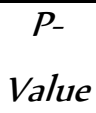 & $\begin{array}{c}\text { Jarque- } \\
\text { Bera }\end{array}$ & $\begin{array}{c}\text { P- } \\
\text { Value }\end{array}$ & & $\begin{array}{c}\text { Jarque- } \\
\text { Bera }\end{array}$ & $\begin{array}{c}P_{-} \\
\text {Value }\end{array}$ & $\begin{array}{c}\text { Jarque- } \\
\text { Bera }\end{array}$ & $\begin{array}{c}P- \\
\text { Value }\end{array}$ \\
\hline Nias & 0.56 & 0.76 & 0.38 & 0.83 & Serdang Bedagai & 0.28 & 0.87 & 0.23 & 0.89 \\
\hline Mandailing Natal & 0.63 & 0.73 & 0.51 & 0.78 & Batu Bara & 0.82 & 0.66 & 0.87 & 0.65 \\
\hline Tapanuli Selatan & 0.45 & 0.80 & 0.53 & 0.77 & $\begin{array}{ll}\text { Padang Lawas } \\
\text { Utara }\end{array}$ & 0.49 & 0.78 & 0.46 & 0.79 \\
\hline Tapanuli Tengah & 0.55 & 0.76 & 0.33 & 0.85 & Padang Lawas & 0.50 & 0.78 & 0.26 & 0.88 \\
\hline Tapanuli Utara & 0.61 & 0.74 & 0.79 & 0.67 & $\begin{array}{l}\text { Labuhanbatu } \\
\text { Selatan }\end{array}$ & 0.33 & 0.85 & 0.78 & 0.68 \\
\hline Toba Samosir & 0.63 & 0.73 & 0.50 & 0.78 & Labuanbatu Utara & 0.49 & 0.78 & 0.64 & 0.73 \\
\hline Labuhan Batu & 0.40 & 0.82 & 0.53 & 0.77 & Nias Utara & 0.34 & 0.84 & 0.45 & 0.80 \\
\hline Asahan & 0.58 & 0.75 & 0.75 & 0.69 & Nias Barat & 0.62 & 0.73 & 0.54 & 0.76 \\
\hline Simalungun & 0.47 & 0.79 & 0.33 & 0.85 & Sibolga & 0.44 & 0.80 & 0.47 & 0.79 \\
\hline Dairi & 0.58 & 0.75 & 0.33 & 0.85 & Tanjungbalai & 0.37 & 0.83 & 0.44 & 0.80 \\
\hline
\end{tabular}




\begin{tabular}{|l|r|r|r|r|l|r|r|r|r|}
\hline Karo & 0.55 & 0.76 & 0.57 & 0.75 & Pematangsiantar & 0.38 & 0.83 & 0.47 & 0.79 \\
\hline Deli Serdang & 0.52 & 0.77 & 0.48 & 0.79 & Tebing Tinggi & 0.34 & 0.84 & 0.51 & 0.78 \\
\hline Langkat & 0.48 & 0.79 & 0.39 & 0.82 & Medan & 0.50 & 0.78 & 0.30 & 0.86 \\
\hline Nias Selatan & 0.47 & 0.79 & 0.47 & 0.79 & Binjai & 0.34 & 0.84 & 0.53 & 0.77 \\
\hline $\begin{array}{l}\text { Humbang } \\
\text { Hasundutan }\end{array}$ & 0.57 & 0.75 & 0.58 & 0.75 & Padangsidimpuan & 0.50 & 0.78 & 0.50 & 0.78 \\
\hline Pakpak Bharat & 0.27 & 0.87 & 0.23 & 0.89 & Gunungsitoli & 0.48 & 0.79 & 0.40 & 0.82 \\
\hline Samosir & 0.83 & 0.66 & 0.66 & 0.72 & & & & & \\
\hline
\end{tabular}

Berdasarkan pengujian yang telah dilakukan, asumsi normalitas pada residual telah terpenuhi. Hal ini terlihat dari signifikansi uji Jarque-Bera yang menunjukkan bahwa nilai probabilitas dari residual masing-masing kabupaten yang lebih besar dari tingkat signifikansi 5 persen. Oleh karena itu, dapat disimpulkan bahwa hipotesis nol tidak dapat ditolak atau dengan kata lain residual berdistribusi normal.

\section{a. Uji Non-Multikolinearitas}

Untuk mendeteksi adanya multikolinearitas, maka dilakukan dengan menggunakan Variance Inflation Factor (FIV). Apabila nilai VIF variabel bebas mempunyai nilai lebih tinggi dari sepuluh, maka terdapat multikolinieritas di antara varibel bebas (Enders, 1989). Adapun formula VIF adalah :

$$
V I F_{k}=\frac{1}{1-R_{k}^{2}} ; \quad k=1,2, \ldots, \mathrm{p}-1
$$

$$
R_{k}^{2}=\frac{S S R}{S S T}=\frac{\sum\left(\hat{x}_{k t}-\hat{x}_{k}\right)^{2}}{\sum\left(x_{k t}-\hat{x}_{k}\right)^{2}}
$$

Tabel. 6 Uji Non-Multikolinearitas

\begin{tabular}{|c|c|}
\hline Variabel & VIF \\
\hline TPT & 2.429438 \\
\hline TPAK & 2.574439 \\
\hline EG & 1.068313 \\
\hline LnPad & 1.986044 \\
\hline LnExp & 4.838162 \\
\hline Amh & 3.322292 \\
\hline Mys & 6.173229 \\
\hline Eys & 2.146599 \\
\hline
\end{tabular}

Dari hasil uji non-multikolinearitas diperoleh bahwa seluruh variabel bebas memiliki VIF yang lebih kecil dari 10. Oleh karena itu disimpulkan bahwa tidak terjadi non-multikolinearitas antara variabelvariabel bebas dalam dalam pemodelan regresi panel. 


\section{Interpretasi Model}

Tabel. 7 Random Error Tiap Kabupaten/Kota untuk Indeks Kedalaman Kemiskinan (Pı) dan Indeks Keparahan Kemiskinan (P2)

\begin{tabular}{lcclcc}
\hline \multicolumn{1}{c}{ Kab/Kota $(\boldsymbol{i})$} & $\hat{\varepsilon}_{i}$ untuk & $\hat{\varepsilon}_{i}$ untuk & \multicolumn{1}{c}{ Kab/Kota $(\boldsymbol{i})$} & $\hat{\varepsilon}_{i}$ untuk & $\hat{\varepsilon}_{i}$ untuk \\
& P1 & P2 & & P1 & P2 \\
\hline Nias & -0.66068 & -0.13142 & Serdang Bedagai & -0.42302 & -0.10811 \\
Mandailing Natal & -0.66573 & -0.18399 & Batu Bara & -0.23649 & -0.06488 \\
Tapanuli Selatan & -0.22517 & -0.09446 & Padang Lawas Utara & -0.51446 & -0.15132 \\
Tapanuli Tengah & 0.254205 & 0.065455 & Padang Lawas & -1.21211 & -0.34356 \\
Tapanuli Utara & 0.298518 & 0.117744 & Labuhanbatu Selatan & -0.01546 & -0.03787 \\
Toba Samosir & 0.538349 & 0.196749 & Labuanbatu Utara & 0.110482 & -0.01148 \\
Labuhan Batu & -0.39795 & -0.09819 & Nias Utara & 1.798795 & 0.497743 \\
Asahan & -0.07059 & -0.02821 & Nias Barat & 1.307753 & 0.334702 \\
Simalungun & -0.11746 & -0.03847 & Sibolga & 0.662662 & 0.169555 \\
Dairi & -0.39558 & -0.06315 & Tanjungbalai & 0.50264 & 0.072627 \\
Karo & 0.385463 & 0.164804 & Pematangsiantar & 0.786348 & 0.231149 \\
Deli Serdang & -0.5075 & -0.09137 & Tebing Tinggi & 0.380512 & 0.089501 \\
Langkat & -0.2182 & -0.0669 & Medan & 1.121503 & 0.284566 \\
Nias Selatan & -0.39205 & -0.09564 & Binjai & -0.62964 & -0.16328 \\
Humbang Hasundutan & -1.34528 & -0.34028 & Padangsidimpuan & -0.21151 & -0.0197 \\
Pakpak Bharat & -1.24257 & -0.36381 & Gunungsitoli & 2.043811 & 0.488881 \\
Samosir & -0.70961 & -0.21742 & & & \\
\hline & & & Kabupaten Gunn & & \\
\hline
\end{tabular}

Nilai intersep akhir diperoleh dengan menjumlahkan variabel $\varepsilon_{i}$ untuk masingmasing kabupaten kota dengan nilai intersep $C$ yang diperoleh dari pemodelan regresi panel dengan random error model (REM). Dari nilai intersep ahir terlihat bahwa
Kabupaten Gunungsitoli, Nias Utara, dan Nias Barat merupakan kabupaten/kota yang memiliki nilai intersep yang tertinggi diantara kabupaten/kota lain di Provinsi Sumatera Utara. Hal ini sejalan apabila diasumsikan kedelapan variabel bebas tidak berpengaruh terhadap indeks kedalaman kemiskinan ( $\mathrm{Pl})$ dan indeks keparahan kemiskinan (P2) maka ketiga kabupaten/kota tersebut merupakan kabupaten/kota dengan 
$P l$ dan P2 yang tertinggi dibandingkan kabupaten/kota lain di Provinsi Sumatera Utara. Begitu juga sebaliknya apabila diasumsikan kedelapan variabel bebas tersebut tidak berpengaruh terhadap (PI) dan (P2) maka yang memiliki indeks kedalaman kemiskinan dan indeks keparahan kemiskinan terkecil adalah Kabupaten Padang Lawas, Pakpak Barat, dan Humbang
Hasundutan. Nilai agregat dari indeks kedalaman kemiskinan (poverty gap) menunjukkan seberapa besar rata-rata pengeluaran penduduk miskin menyimpang terhadap garis kemiskinan. Sementara itu, indeks keparahan kemiskinan (poverty severity indeks) memberikan informasi mengenai gambaran penyebaran pengeluaran diantara penduduk miskin.

Tabel. 8 Hasil Pengujian Random ErrorModel Indeks Kedalaman Kemiskinan (PI) dan Indeks Keparahan Kemiskinan (P2)

\begin{tabular}{|c|c|c|c|c|c|}
\hline \multicolumn{3}{|c|}{ Persamaan REM Indeks Kedalaman Kemiskinan (PI) } & \multicolumn{3}{|c|}{ Persamaan REM Indeks Keparahan Kemiskinan (P2) } \\
\hline Variabel Bebas & Koefisien Regresi & t-hitung & Variabel Bebas & Koefisien Regresi & t-hitung \\
\hline$C$ & $\left.23,50566^{\star * *}\right)$ & 2,850204 & $C$ & $\left.6,313263^{* *}\right)$ & 2,431849 \\
\hline TPT & 0,021829 & 1,093270 & TPT & 0,011081 & 1,396517 \\
\hline TPAK & $-0,001395$ & $-0,152034$ & TPAK & $-0,001510$ & $-0,443627$ \\
\hline EG & 0,030486 & 1,0038333 & EG & $-0,013028$ & 1,055772 \\
\hline LnPAD & $-0,025634$ & $-0,302186$ & LnPAD & $-0,005078$ & $-0,159612$ \\
\hline $\operatorname{LnExp}$ & $\left.-2,2846740^{* * *}\right)$ & $-2,922764$ & $\operatorname{LnExp}$ & $\left.-0,868802^{* * *}\right)$ & $-2,837827$ \\
\hline $\mathrm{AMH}$ & $\left.0,058677^{* * *}\right)$ & 2,824410 & $\mathrm{AMH}$ & $\left.0,023984^{* * *}\right)$ & 2,934220 \\
\hline MYS & $\left.-0,259707^{*}\right)$ & $-1,753868$ & MYS & $\left.-0,084395^{*}\right)$ & $-1,746013$ \\
\hline EYS & 0,07893 & 0,749716 & EYS & 0,037156 & 0,908156 \\
\hline \multicolumn{2}{|l|}{ R-Squared } & 0,229733 & \multicolumn{2}{|c|}{ R-Squared } & $=0,219233$ \\
\hline \multicolumn{2}{|c|}{ Adjusted R-Squared } & 0,179634 & \multicolumn{2}{|c|}{ Adjusted R-Squared } & $=0,168451$ \\
\hline \multicolumn{2}{|l|}{ F-Statistic } & 4,585613 & \multicolumn{2}{|c|}{ F-Statistic } & $=4,317167$ \\
\hline \multicolumn{2}{|c|}{ Prob (F-Statistic) } & 0,000065 & \multicolumn{2}{|c|}{ Prob (F-Statistic) } & $=0,000131$ \\
\hline \multicolumn{2}{|c|}{ Durbin Watson stat } & $=2,060211$ & \multicolumn{2}{|c|}{ Durbin Watson stat } & $=1,877852$ \\
\hline
\end{tabular}

Keterangan :

***) signifikan pada $\quad \alpha=1$ persen

$\left.{ }^{* *}\right)$ signifikan pada $\quad \alpha=5$ persen

*) signifikan pada $\quad \alpha=10$ persen

Dari tabel 8 di atas diperoleh bahwa nilai $R$-squared pada regresi panel dengan Random Effect Model hanya mencapai 22,97 persen untuk pemodelan variabel bebas terhadap Indeks Kedalaman Kemiskinan (PI) dan hanya mencapai 21,92 persen terhadap Indeks Keparahan Kemiskinan (P2). Hal ini menunjukkan bahwa kedelapan variabel 
bebas yang digunakan dalam penelitian hanya mampu menjelaskan sebesar 22,97 persen terhadap variasi Indeks Kedalaman Kemiskinan (PI) dan sebesar 21,92 persen terhadap variasi Indeks Keparahan Kemiskinan (P2) dan sisanya dijelaskan oleh variabel-variabel lain. Nilai Adjusted $R$ Square juga menunjukkan angka yang

cukup kecil yang berarti bahwa kedelapan variabel bebas hanya mampu menjelaskan keberagaman (variasi) variabel Pl sebesar 17,96 persen dan variabel P2 sebesar 16,84 persen sisanya dijelaskan oleh variabel lain yang tidak masuk dalam model dimana penambahan variabel bebas tidak akan memengaruhi nilai variasi.

Berdasarkan hasil pengolahan uji statistik, diperoleh bahwa dari delapan variabelbebas yang digunakan dalam penelitian, hanya variabel pertumbuhan pengeluaran rumah tangga (LnExp), Angka Melek Huruf (AMH), dan Rata-Rata Lama Sekolah (MYS) yang berpengaruh signifikan terhadaplndeks Kedalaman Kemiskinan (PI) dan Indeks Keparahan Kemiskinan (P2). Variabe pengeluaran rumah tangga dan ratarata lama sekolah berpengaruh negatif terhadap indeks kedalaman kemiskinan dan indeks keparahan kemiskinan sementara variabel angka melek huruf (AMH) justru berpengaruh positif terhadap Indeks kedalaman kemiskinan dan indeks keparahan kemiskinan. Adapun pertumbuhan pengeluaran rumah tangga sebesar 1 persen akan mampu menurunkan angka indeks kedalaman kemiskinan (PI) sebesar 2,28 satuan dan indeks keparahan kemiskinan sebesar 0,8 satuan dengan asumsi variabel lain tetap. Sementara itu peningkatan ratarata lama sekolah (MYS) sebesar 1 satuan akanmampu menurunkan angka indeks kedalaman kemiskinan (PI) sebesar 0,26 satuan dan menurunkan angka indeks keparahan kemiskinan (P2) sebesar 0,08 satuan.

\section{Simpulan}

Model terbaik pada pemodelan ekonometrika regresi data panel untuk Indeks Kedalaman Kemiskinan (PI) dan Indeks Keparahan Kemiskinan (P2) pada kabupaten/kota di Provinsi Sumatera Utara adalah model Random Effects (REM), dimana terdapat efek cross section dan efek waktu terhadap pemodelan. Dari hasil yang diperoleh, nilai $R$ Squaremencapai 22,97 persen untuk Indeks Kedalaman Kemiskinan (PI) dan 21,92 persen untuk Indeks Keparahan Kemiskinan (P2). Hasil penelitian juga menunjukkan bahwa 3 dari 8 variabel bebas yang digunakan dalam penelitian berpengaruh signifikan terhadap variabel respon, yaitu pertumbuhan pengeluaran rumah tangga (LnExp) dan rata-rata lama sekolah (MYS) yang berpengaruh negatif dan angka melek huruf (AMH) yang berpengaruh positif terhadap indeks kedalaman kemiskinan (PI) dan indeks keparahan kemiskinan (P2).

\section{DAFTAR PUSTAKA}

Agus Widarjono. 2009. Ekonometrika Pengantar dan Aplikasinya, Edisi Ketiga, Ekonesia . 
C. Hsiao. 1986. Analysis of Panel Data,

Cambridge: Cambridge University

Press.

Fajriah Nur \& Rahayu Puteri Santi. 2016.

Pemodelan FaktorFaktor yang

Mempengaruhi Kemiskinan

Kabupaten/Kota di Jawa Timur

Menggunakan Data Panel. Jurnal,

ITS.

Greene, W. H. (2003). Econometric

Analysis (5th ed.). New Jersey:

Pearson Education, Inc.

Gujarati, Damodar. 2003.Ekonometri Dasar.

Terjemahan: Sumarno Zain, Erlangga.

Nachrowi, D.N, dan Usman, Hardius.

(2006). Pendekatan Populer dan

Praktis Ekonometrika untuk Analisis

Ekonomi dan Keuangan. Jakarta:

Lembaga Penerbit Fakultas Ekonomi

Universitas Indonesia (LP-FEUI).

Setiawati Kurnia A. \& Setiawan. 2012.

Pemodelan Persentase Penduduk

Miskin di Jawa Timur degan

Pendekatan Ekonometrika Panel

Spasial. Jurnal, ITS.

Wijaya Tony, (2009) . Analisis data

penelitian menggunakan SPSS.

Yogyakarta : Universitas Atma Jaya. 